\title{
TECHNOLOGY TRANSFER AND SCIENTIFIC RELEVANCE
}

\author{
By Porter Hoagland and Hauke Kite-Powell
}

. . W We must test the hypotheses that link economic and societal benefits directly to advances in research. All research is not the same. What kinds of research offer the greatest probability of improving the quality of life of humankind throughout the world? Should not applied research, and policy research, be recognized as essential elements of the fabric of research? If scientists are not willing to rigorously and fearlessly confront-and answer-these types of questions, then they cannot claim, and surely will not achieve, a stronger grip on federal purse strings than other special interest groups.

Hon. George Brown (1992)

. . technology

transfer refers to

the dissemination

of new knowledge

from a source . . . to

recipients . . . who

benefit in some

way from the

knowledge.
G Joverment has become preoccupied with the "relevance" of science. Congressman George Brown. Chairman of the U.S. House Committee on Science, Space, and Technology, now leads the fight in the United States to "rethink" science policy to ensure that scientific research is linked more directly to national goals such as economic competitiveness, public health, national security, and environmental protection, among others (Task Force on the Health of Research 1992).

Two important considerations should be addressed in the emerging debate. Congressman Brown has focused mainly on the first: given limited budgetary resources and prespecified (albeit somewhat general and therefore vague) national goals, how can we, as a society, best establish scientific and technological research priorities?

The second consideration is related to the first. How can scientific research results be disseminated and applied in a way that fosters the achieving of national goals? This consideration is sometimes referred to broadly as "technology transfer."

Just what is technology transfer? Everyone from science administrators to policy analysts employs the term loosely, as if they understand exactly what it means. President Clinton wants to intensify it (Chapman. 1992). The U.S. Council on Competitiveness (COC, 1992) wants to reprioritize existing funds for it, but U.S. federal laws that govern and encourage technology transfer do not bother to define it.

P. Hoagland and H. Kite-Powell. Marine Policy Center. Woods Hole Oceanographic Institution, Woods Hole, Massachusetts 02543, USA.
Within the last decade, much discussion has been generated about the concept, yet it is remarkable that few have attempted to think carefully and clearly about the meaning of the term. In this article, we begin to probe the meaning of "technology transfer" and, in the process, we identify issues worthy of serious consideration by institutions and scientists engaged in technology transfer.

The oceanography community comprises a diversity of institutions including federal laboratories, universities, private nonprofit research institutions, and commercial firms. All of these institutions engage in technology transfer. Recent federal policies have focused mainly on technology transfer from federal laboratories (Table 1. Fig. 1). In this article, we examine the technology transfer issue primarily as it relates to universities and private nonprofit research institutions, which, other than commercial firms, are the most numerous in oceanography (see Fig. 2). By far the most important federal policy for these institutions is the Bayh-Dole Act of 1980, which allows institutions conducting research under federal government sponsorship to claim title to intellectual properties (patents) arising from their research efforts (see Table 2).

In general terms, technology transfer refers to the dissemination of new knowledge from a source, such as a research laboratory, to recipients, such as commercial firms, other researchers, or the public, who benefit in some way from the knowledge. Technology transfer is linked to the process of new knowledge creation. and it involves many issues that are fundamentally economic. We therefore adopt an economic approach to understanding it. 


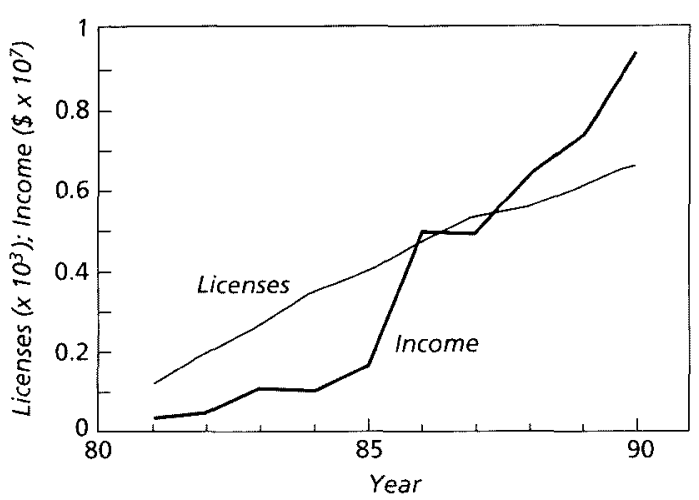

Fig. I: Cumulative number of federal patents licensed and license income in current dollars during the period 1981-1990 (after GAO. 1991). During this period several federal laws were enacted and presidential executive orders were issued pertaining to technology transfer (Table 1). Policies are found in the U.S. Code listing as 15 USC $\$ 3701$ et seq. See also Gaffney (1992) for a summary of provisions of these policies relevant to technology transfer from federal laboratories.

\section{Technology as New Knowledge}

Laymen often conceptualize technology as hardware (ROVs, XBTs. CTDs, ECDIS, sonar, etc.). This conceptualization is too narrow, especially when considering technology transfer in oceanography, a field in which scientists engage in research that results in ideas, theories, and other valuable information as well as hardware (see McTague, 1988). We suggest the more general view that technology is essentially information about how to do things. We are concerned primarily with the creation and dissemination of a special kind of such technological information: new knowledge.

New knowledge can be characterized by its utility in consumption (usefullness to individuals as a consumption good) or its productivity as capital (contribution to a production process). One example of knowledge creation as an individual consumption good is the existence of associates

Table 1

Federal technology transfer policies.

\begin{tabular}{cc}
\hline Year & \multicolumn{1}{c}{ Title of Act or Executive Order } \\
1980 & $\begin{array}{c}\text { Stevenson-Wydler Technology Innovation Act } \\
\text { (P.L. 96-480) } \\
\text { Bayh-Dole Patents and Trademarks Act (P.L. 96-517) }\end{array}$ \\
1986 & $\begin{array}{l}\text { Federal Technology Transfer Act (P.L. 99-502) } \\
1987\end{array}$ \\
$\begin{array}{c}\text { Facilitating Access to Science and Technology } \\
\text { (E.O. 12591) } \\
\text { Uniform Treatment of Federally Funded Inventions } \\
\text { (E.O. 12618) }\end{array}$ \\
1988 National Technical Information Act (P.L. 100-519) \\
1989 & $\begin{array}{c}\text { National Competitiveness Technology Transfer Act } \\
\text { (P.L. 101-189) }\end{array}$ \\
1990 & Defense Authorization Act (P.L. 101-510) \\
\hline
\end{tabular}

programs, through which individuals make direct contributions to others at a research laboratory. As a public consumption good, new knowledge resembles art. We value new knowledge for its own sake, and we value the fact that our collective understanding of the natural world is being expanded by the efforts of researchers to generate new knowledge (Kaysen, 1966: Rottenberg, 1968).

As a capital good, new knowledge is employed as an input to an economic production process. New knowledge contributes to the production of goods and services in much the same way that raw materials, machinery, and labor do. More specifically, new knowledge can affect the mix of inputs in a way that increases the net benefits that can be realized from a productive process.

A related distinction exists between basic and applied research. According to the National Science Foundation (NSF), basic research is designed to further "knowledge or understanding of the fundamental aspects of phenomena and of observable facts without specific applications toward processes or products in mind." Applied research is intended to help determine "the means by which a recognized and specific need may be met" (NSF, 1982). New knowledge resulting from applied research is by definition more likely to be useful as a capital good than knowledge produced as a result of basic research.

New knowledge can be created in fields of either science or technology. Dasgupta and David (1986) identified science and technology as separate social institutions on the basis of "attitudes" toward the creation of new knowledge. A social institution in the sense of Dasgupta and David (1986) is not equivalent to an individual research lab or a specific group of research laboratories. It is quite possible for some scientists within a research laboratory to be part of the science institution and some to be part of the technology institution. In fact, one scientist might split her time between the two. The science institution considers new knowledge to be useful primarily for public consumption (especially by other scientists). Its norms reflect this attitude. Free and open disclosure of new knowledge is one of the principal norms of science. On the other hand. the technology institution considers new knowledge to be useful primarily as a capital good. A rule (if not a norm) of technology is to keep new knowledge secret, or at least away from competitors.'

Whether or not new knowledge resembles art or capital. is categorized as basic or applied, or is called science or technology, it differs from most other inputs to production in one significant way: it

\footnotetext{
'Thus the potential for conflicts of interest when a scientist or a research laboratory spans both science and technology.
}

New knowledge

resulting from applied

research is by

definition more likely

to be useful as a

capital good than

knowledge produced

as a result of basic

research. 


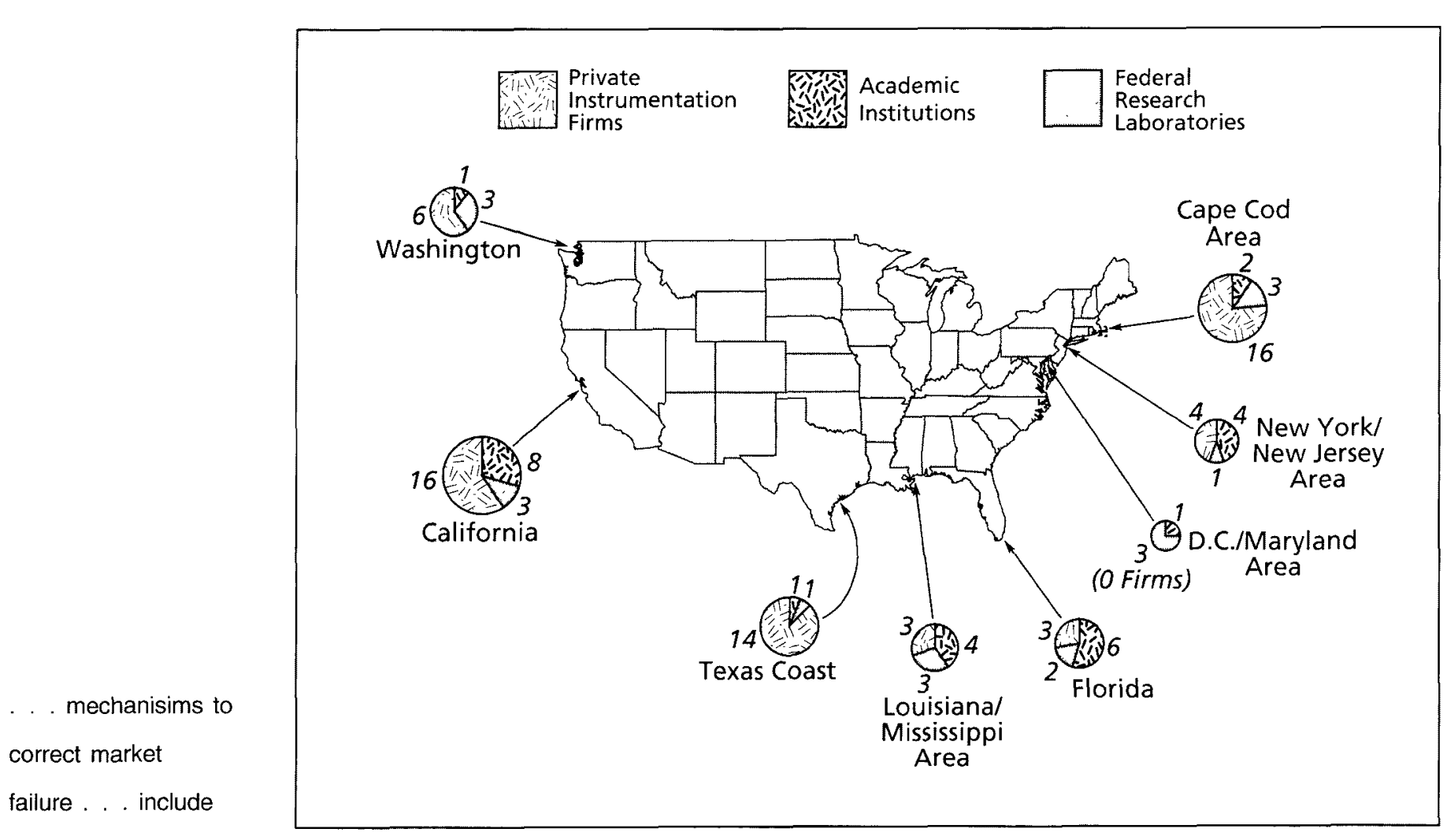

direct goverment

funding of research

and protection of

intellectual property.

Fig. 2: Number and geographic distribution of institutions involved in oceanographic research for regions that have more than three laboratories or institutions, or more than five firms. The clustering of instrumentation firms around research institutions illustrates a "spawning ground" effect that is one form of technology transfer (Broadus et al., 1988).

has the nonconsumptive and nonrival attributes of a public good. Once new knowledge is created, it cannot be used up no matter how many firms or individuals make use of it (although it can appreciate through use or depreciate from lack of use). Furthermore, it is costly for the "owner" of new knowledge to use it without revealing at least a part of it to others (information "leaks out" or "spills over").

\section{New Knowledge Investments}

Given the public good characteristics of new knowledge, anyone with an interest might benefit from it at relatively little cost. But creating this new knowledge in the first place-through research, discovery, and invention-is costly. Under normal commercial circumstances we expect private firms or individuals to shy away from investing in the creation of new knowledge, preferring

: Strictly speaking, we expect that the attractiveness of investment in new knowledge creation relative to other kinds of investments is affected adversely by the public good nature of new knowledge. It is still likely to be the case that some new knowledge investments have relatively high expected payoffs after research costs and therefore would be undertaken anyway. Another factor affecting the investment in $R \& D$ is uncertainty associated with its outcome. See Dasgupta and Maskin (1987) for an analysis of issues associated with investment in R\&D. instead to wait for others to create it. ${ }^{2}$ Therefore, from the viewpoint of society and in the absence of government intervention or private philanthropy, it is possible that too little effort will be devoted to the creation of new knowledge. This situation is a classic example of what economists call a "market failure."

Society has developed mechanisms to correct this kind of market failure. Although these mechanisms are hardly precise, we suspect they are beneficial because they result almost certainly in the creation of more new knowledge than would be created otherwise. ${ }^{3}$ Two mechanisms important in oceanography include direct government funding of research and the protection of intellectual property.

Even with government sponsorship at a research laboratory, individual scientists might be reluctant to apply their best efforts in the creation of new knowledge for the reasons discussed above. But the institution of science has developed

Two additional problems arise here. Government intervention itself is costly due to rent seeking (which may result in "academic pork"), excessive regulation, and administrative costs. Moreover, it is possible that corrective mechanisms overcorrect and that too much effort is devoted to the production of information. We address the latter issue below. 
Table 2

Bayh-Dole Patents and Trademarks Act of 1980: a summary of provisions

relevant to research laboratories.

1. Unless provided otherwise in a funding agreement, nonprofit organizations (universities, research laboratories) may elect to retain title to "subject inventions."

2. "Subject inventions" are inventions conceived or first actually reduced to practice in the performance of work under any contract, grant, or cooperative agreement between a federal agency and a contractor for experimental. developmental. or research work funded in whole or in part by the federal government.

3. The federal government receives the title to a subject invention unless within a reasonable time the research Iaboratory: I) discloses the subject invention; 2 ) makes an election to retain title after disclosure: and 3) files patent applications.

4. The federal contracting agency receives a nonexclusive, nontransferable, irrevocable, paid-up license to practice or have practiced for or on behalf of the United States any subject invention.

5. The federal agency may require periodic (confidential) reporting on the utilization or efforts at obtaining utilization of a subject invention by the research laboratory or its licensees.

6. Assignment of patent rights by a research laboratory requires approval of the federal agency (unless assignment is to an "invention management organization," which in turn must seek approval for patent assignments).

7. Granting of exclusive licenses is prohibited unless granted to a small business firm: exclusive licenses are limited in duration (unless approval for a longer duration is granted by the federal agency).

8. The research laboratory must share royalties with the inventor.

9. After sharing royalties with the inventor and covering administrative costs, the balance of royalties or income must be utilized for the support of scientific research or education.

10. The inventor can request the grant of title to the invention from the federal agency if the research laboratory does not elect to retain title.

11. The federal agency may require research laboratories to license inventions that are not subject inventions if necessary to achieve the practical application of the subject invention.

12. Under certain circumstances, the federal agency can "march-in" to require the research laboratory to grant a license.

13. Licensees must agree that products embodying the subject invention or produced through the use of the subject invention will be manufactured substantially in the United States (possible waiver upon showing of reasonable but unsuccessful effort to find potential licensees that meet this requirement).

an ingenious "incentive compatible" mechanism: the existence of a contest with a single winner helps to motivate the efforts of individual scientists (Dasgupta and David, 1986). In science the winner's prize is the priority of discovery and its attendant recognition. Even more remarkably, the contest permits the dissemination of new knowledge, which can then be employed in productive processes (including other new knowledge creation processes) at low cost.

\section{Government-Sponsored Research}

The most important source of funding for oceanographic research at universities and private nonprofit research institutions is the federal government. MacDonald et al. (1991) estimate that the U.S. government now spends roughly $\$ 1.4$ billion annually on oceanographic research of all types. The U.S. Navy historically has been the largest source of funding; that may change as Navy priorities change and technological development budgets shrink in the post-Cold War era (OSB, 1992). Government spending on oceanographic R\&D is a poor and often misleading proxy for the value of oceanographic research (although it is often cited as such). Government decisionmakers would prefer to know all of the benefits and costs associated with different levels of the research activity. If these data were available, then the decisionmakers might examine the effects of incremental changes in funding or policies designed to encourage research.

Oceanographic research creates new knowledge, which may or may not be marketable in a commercial sense. If new oceanographic knowledge is not commercially marketable but is still perceived as valuable, in the sense of a scientific advancement for example, a determination of its precise economic value can be problematic.

In the United States and in other industrialized countries, mission-oriented government research laboratories are important sources of new knowledge. In oceanography, mission-oriented research laboratories include those owned or operated by

\footnotetext{
- We expect that new knowledge that is not immediately commercially marketable can have value as a capital good (usually in combination with other new knowledge and other inputs in the long term. Some attempts have been made to estimate society's rate of return on investment in research of this type. For example, Mansfield (1991) has attempted to evaluate worldwide investments in academic R\&D from 1975 to 1978 that resulted in products during 1982 to 1985 . His estimate of the social rate of return on investments during this period is $28 \%$.
}

\section{Goverment}

spending on

oceanographic R\&D

is a poor... proxy

for the value of

oceanographic

research. 
the Navy, National Oceanic and Atmospheric Administration (NOAA), U.S. Geological Survey, Coast Guard, and the Environmental Protection Agency. Although mission-oriented research laboratories are sponsored by government. their existence and activities are not necessarily the result of government efforts to correct for underinvestment in the creation of new knowledge. Instead. the research efforts of mission-oriented laboratories are directed mostly at meeting the specific objectives of government agencies. These objectives are likely to be aimed at providing other types of public goods such as national security, navigational aids, and environmental protection.

\section{Intellectual Property}

Intellectual property, such as patents, ${ }^{5}$ is another way in which government can motivate investment in new knowledge creation. Analogous to the rule of priority in science, patents (but not trade secrets) encourage the disclosure and wide dissemination of new knowledge and reward the efforts of the inventor. Patents provide an incentive for early disclosure (ignoring for the moment. strategic commercial considerations) in the form of a 17-year monopoly on the manufacture, use, or sale of an invention.

To correct for potential underinvestment in research, private property rights are created in information through intellectual property protection (at some cost of creating the rights, monitoring and enforcing them, and, potentially, putting up with the monopoly). In effect, intellectual property protection changes the nature of information as a commodity so that a market in information can perform better.

If research projects are viewed as identical in all relevant aspects, then the establishment of intellectual property rights may result in an overcorrection of the market failure problem. When a "winner takes all" with a patent (or even with priority in science), then races among competing teams in science or technology may stimulate excessive investment in the creation of new knowledge. In effect, there could be an unnecessary duplication of effort because once new knowledge is produced, there is no value in producing it again. But we must be a little careful here. Even within a specific field, not all similar research projects are aimed at solving precisely the same problem, nor do they take the same approach. As a result, research projects that appear to be identical on the surface can be in fact complementary."

'Other forms of intellectual property include copyrights. trademarks, tangible research property, trade secrets. mask works. among others. See Smith and Parr (1989) for a useful summary. In this article, we focus on patents as an example.

"Allen (1991) cautions against unsubstantiated assumptions about overinvestment (or underinvestment) in new knowledge creation. Research projects are more realistically viewed as differentiated imperfect substitutes for one another-and quite possibly as complementary.

\section{A Balancing Act}

In the simplified world we have described, science and technology policy is seen as an attempt at achieving a balance: policymakers trade off the potential for underinvestment by adopting policies that increase the likelihood for overinvestment. But because it is impossible to tailor policy to balance these two effects for every research activity, science and technology policymaking can be viewed as only a very blunt instrument for achieving social goals. For example, it is unlikely that a 17-year patent period is socially optimal for every invention. but policymakers believe on average that this characteristic of the patent system provides a nudge in the right direction for new knowledge investments.

\section{Technology Transfer}

Information or new knowledge can be disseminated in different forms. including spoken words, publications, computer software, and embodiment in instruments and machines. (Technology "licensing" is one kind of technology transfer in which new knowledge is traded for other considerations-usually financial.)

New knowledge is valuable only if it can be transferred from its source to scientists and engineers who can use it in their own research efforts. to commercial firms that employ it as an input in productive processes, to government agencies that apply it toward achieving their own objectives, or to individuals who appreciate it per se. From society's perspective. information should be transferred in a form and manner that results in the greatest net benefits.? The question at the heart of the technology transfer issue then is: What is the most efficient way in which to transfer new knowledge from its source to end users?

We can make some generalizations about dissemination from different types of research laboratories. A significant portion of the dissemination of new knowledge at scientific research laboratories and universities occurs through the publication of peer-reviewed journal articles, books, technical reports, working papers, etc. For many research laboratories in the field of oceanography, this is the predominant form of technology transfer. (This method may be the only sensible transfer mechanism for basic research results.) For mission-oriented, federal research laboratories (e.g., in the defense or energy fields) a significant portion of new knowledge is

Note that this perspective may not be completely consonant with the point of view of a research laboratory (see box) Absent any restrictions imposed on it by government, a research laboratory might well choose a form of transfer that is not socially optimal in an economic sense. An extreme example from another field is the case of the Dead Sea Scrolls, in which researchers restricted public access to archaeological information for an extended period of time. 
conveyed to the sponsor, usually a government agency, which may in turn transmit the new knowledge to a limited set of commercial firms or perhaps more widely. Likewise, research laboratories operated by private firms attempt to keep new knowledge in-house or seek to sell it in intellectual property markets.

Although we have distinguished between the two, technology transfer cannot be analyzed independently from new knowledge creation, because technology transfer policies can also influence the effort devoted to the creation of new knowledge. Changes in public policies that encourage licensing relative to open scientific dissemination may have a measurable effect on the priorities for new knowledge creation. We might expect two kinds of effects: 1) a decrease in the ratio of basic to applied (commercially oriented) research efforts and 2) an enhanced potential for conflicts of interest faced by scientists (Hoagland and Kite-Powell, 1989). We expect both effects to involve costs, but, to our knowledge, empirical data that describe the sign or size of these effects are not yet available.

As a result of this linkage, the problem for society is to select incentives for new knowledge creation in combination with a set of mechanisms for efficient technology transfer. The Bayh-Dole Act (Table 2) is one example of a change in this combination of incentives. As a result of this act, we expect that some of the efforts of some scientists now are devoted more toward patenting and less toward publishing. If the patents are licensed, then clearly the Bayh-Dole Act can be beneficial for the univer- sities and nonprofit research laboratories whose scientists conduct research under government sponsorship. But is the act (or, more generally, the set of national policies that emphasize technology transfer) beneficial to society as a whole?

\section{Scientific Relevance}

One might reasonably inquire as to the need for additional incentives (e.g., title to patent rights) for institutions or for scientists to create new knowledge. Their research is being funded already by government agencies, and the rule of priority in science helps to motivate their efforts. We believe that one explanation for a policy shift such as the Bayh-Dole Act is found in the search for scientific relevance.

In the face of government budget constraints and foreign economic competition and with only indirect evidence of the links between basic scientific research and U.S. industrial performance, Congress has encouraged a shift toward new knowledge creation that is commercially valuable as a capital good. Industrial interest in the licensing of results from federally sponsored research is seen by Congress as evidence of the relevance of science in achieving national goals such as economic competitiveness. Somewhat analogously, as the national defense support mission of some federal research laboratories becomes less important in the post-Cold War era, the ability of these laboratories to conduct "dual use" research that is licensable to the private sector will become more important as an indicator to Congress of the rele-
. . . a policy focus

on technology

licensing from

universities and

goverment-sponsored

laboratories may be

misdirected.

\section{A Research Laboratory's Problem}

In its simplest form, technology licensing is a relationship between a research laboratory and one or more commercial firms.' We describe here a bargaining problem in which the parties are engaged in a long-term relationship. Imagine an agreement in which the research laboratory trades its new knowledge for a fixed fee and a royalty that is a percentage of the sales of a commercial product. The basic problem faced by the research laboratory is to structure a relationship (sometimes with the help of the firm) so that the commercial firm willingly enters into an agreement and performs according to the wishes of the research laboratory.

The literature on technology licensing focuses on many different types of arrangements (Reinganum, 1989), but only one of these types concerns us here. An independent research laboratory creates new knowledge or information that has the potential for lowering the costs of producing an existing product in a commercial market "downstream" or that has the potential for bringing about a new product introduction. The product can be either a good (e.g., a new type of expendable oceanographic instrument) or a service (e.g., a new geophysical prospecting technique).

\footnotetext{
'In the economics literature, this is known as one kind of "principal-agent" problem, in which the research laboratory is principal and the firm is agent. One can easily imagine the reverse relationship: a commercial firm "hires" the R\&D services of a marine research laboratory. In this case, the commercial firm is principal, the laboratory is agent. The agency problem that we describe is nested in a matrix of possible agency relationships: the public is principal, the Congress is agent; the Congress is principal, the National Science Foundation (NSF) is agent: NSF is principal, the marine science laboratory is agent; and so on. The important feature is that the outcome of a principal-agent relationship is a random variable that depends upon an action taken by the agent. The principal designs the contract (sometimes in collaboration with the agent). See generally Arrow (1985). In this article. we abstract from the complexity of reality to highlight certain important features of the technology transfer relationship.
} 
vance of the research conducted at these laboratories. (As shown by Fig. 1, we have seen licensing from the federal laboratories increase in step with the implementation of technology transfer policies, but the volume of licensing and the size of the revenues are both still small.)

But even if they appear to make science more relevant, we cannot say conclusively whether or not the new technology transfer policies are optimal (or even beneficial) for the United States. Feller (1990) concludes that there is little reason to believe that the net present value of efforts to reallocate and commercialize faculty research efforts will be positive, except in the cases of a few academic institutions. Technology licensing may involve significant administrative costs to garner a return with a very low probability. Moreover, Feller (1990) concludes that scientists may be more efficient at providing new knowledge for open dissemination than as financially interested entrepreneurs packaging new knowledge for private or institutional gain. In other words, society might well prefer that scientists transfer their "technologies" through the medium of scientific journals or other open academic channels rather than the patent system.

In fact, it is quite possible that a policy focus on technology licensing from universities and government-sponsored research laboratories may be misdirected. Nelson (1986) has investigated the role that university research plays in industrial technical advances:

\section{...publication of}

results continues to

be the most important

form of technology

transfer in

oceanography.
We examine here the case where new knowledge has been developed with funding from an uninterested sponsor, such as a government agency.' Thus firms in the downstream industry have no involvement in the development of the new knowledge. From a historical standpoint, we believe that this is a common case, because industrial funding for research in the field of oceanography has been minor, well below the national average for industrial funding of academic R\&D (Hoagland and Kite-Powell, 1989). However. we believe also that in the future it is quite possible that a larger fraction of technology licensing transactions will involve initial commercial sponsorship. Some observers have paid attention to this more complicated type of relationship (e.g.. Tirole, 1988: 411-412), but we do not address it in this article.

The research laboratory may be constrained from entering the downstream market as a manufacturer for legal or economic reasons or because of an internal policy that prohibits it. Many research laboratories have established commercial subsidiaries (also known as "technology transfer organizations") that allow them to relax the legal constraint. For example, the Woods Hole Oceanographic Institution has recently established the Quissett Development Corporation for this purpose. Economic reasons might include strategic actions taken by firms already in the market to preclude other firms from participating, the relationship between market demand (small) and minimum efficient scale of production (large) so that there may be "no room" for a new firm in the market, or simply a lack of experience and interest in manufacturing.

The research laboratory would like to trade property rights to the new knowledge (by license or other arrangement) to one or more downstream firms for financial remuneration. The research laboratory's primary objective is to maximize the financial remuneration it receives in the transaction. $\mathrm{Re}$ search laboratories engaged in technology licensing might have additional objectives such as "fairness" to industry or compliance with norms of the scientific research community that may conflict with the revenue maximization objective. In general, we expect that any attempt to achieve more than one objective will have the effect of reducing the size of financial remuneration potentially recoverable by the research laboratory.

The best way for the research laboratory to structure a transaction with downstream firms to achieve an objective of revenue maximization depends upon a number of important factors. The most prominent of these factors include the following: the degree of understanding about the value of the new knowledge by the research laboratory and firms in the downstream industry, the organization of the industry in the downstream market, the financial terms of the transaction. and the costs of transaction. To achieve the objective, it is important that research laboratories engaged in technology licensing give consideration to all of these factors. ${ }^{+}$

2In other words, the government agency has no direct financial interest in the new knowledge.

${ }^{2}$ Using the Woods Hole Oceanographic Institution as an example from oceanography, in 1989 industrial support of R\&D was $1.2 \%$ of total support compared to $7.3 \%$ nationally for academic R\&D (NSB, 1991).

+ Other issues that should be addressed by research laboratorics engaged in technology transter include the ease with which the new knowledge can be replicated by downstream firms (inventions that can be copied without infringing intellectual property rights), the number of licenses to issue to downstream firms, whether or not to issue more than one license to individual firms. whether or not to allow sublets, formulating an understanding of whether or not the invention is "drastic" (a new product or a "process" invention that reduces the costs of production to a level at which a firm with an exclusive license could set a monopoly price and still undercut the costs of other firms in the market). 
"My interpretation is that university research rarely in itself generates new technology; rather it enhances technological opportunities and the productivity of private research and development in a way that induces firms to spend more in both the industry in question and upstream."

Consistent with Nelson's suggestion, Berman (1990) has found that increased direct funding of collaborative university-industry $R \& D$ leads to subsequent increases in industry $R \& D$ expenditures, after a median lag of 5 years.

We do not raise these points to suggest that policy shifts that emphasize technology licensing are completely unfounded. It makes sense to many in the science and technology field for public policy to encourage flexibility in the way in which technology transfer is conducted by research laboratories. However, an equally sensible focus for policy could well be an increase in funding for academic research or specific encouragements, in tax policy perhaps, that foster collaborative research. ${ }^{8}$

\section{Conclusions}

Technology is not just hardware; it should be defined more broadly as information (new knowledge) developed as a result of research. As such, it has the economic attributes of a public

${ }^{8}$ The concept of the "cooperative research and development agreement" (CRADA) between federal laboratories and other institutions is evidence of a step in this direction. good. Because new knowledge is a public good, we expect that industry will fail to make what society would consider to be optimal investments in its creation. Two corrective policy tools are as follows: (1) direct government sponsorship of basic and applied research and (2) the creation of intellectual property. The first has always been of premier importance to the field of oceanography because it consists of basic research on natural phenomena and applied research toward noncommercial mission-oriented goals, such as environmental protection, coastal hazards, or national defense.

The problem of technology transfer is to identify efficient means for new knowledge dissemination. The licensing of commercially valuable research results is one form of technology transfer. As we understand technology to be new knowledge created through research and development, scientific publication is another form of technology transfer-although it is not widely recognized as such. Technology transfer is linked to the process of knowledge creation; for example, policies that encourage technology licensing may result in a shift from basic to applied research efforts (especially commercially oriented ones) and possibly a reduction in scientific publication. Therefore technology transfer policy must be analyzed as a component of more general policies to encourage new knowledge creation.

The Bayh-Dole Act is the most important recent change in technology transfer policy for research institutions. The act encourages the licensing of re-
Technology transfer

is linked to the

process of knowledge

creation . .
How does the research laboratory know the value of its intellectual property? "The value of a patent on a cost-reducing innovation [is] the revenue which an innovator could acquire by licensing the innovation to producing firms" (Arrow, 1962). In theory, this value might be known with certainty by either the research laboratory (Gallini and Wright, 1990), the downstream firm(s), or both (Katz and Shapiro, 1986). In practice, we expect that both the research laboratory and the potential licensee will be uncertain about the value of the invention. At best, each party might be able to assign a probability distribution over a range of possible values. Often the balance of understanding is tilted in the private firm's favor, because research laboratories tend to know less about production costs and markets. As a consequence, the research laboratory may have only a vague idea of the value of its technology, based upon interest expressed by potential licensees.

From the research laboratory's perspective, uncertainty about the value of an invention is not necessarily costly if several firms express an interest in the new knowledge. These firms then might compete for the rights to the knowledge through an auction process. Under some fairly unrestrictive assumptions, theory predicts (and empirical research has tended to confirm) that, in the absence of collusion among firms bidding in an auction, competition among firms in this manner will yield for the research laboratory the winning bidder's expected value of the license-minus the costs of holding the auction.

More common is the case that a technology licensing relationship will arise between a research laboratory and a single downstream firm. In this situation, the two parties must haggle over value. Holding other things constant, a negotiating advantage rests with the party that has a better estimate of the value of the new knowledge..$^{5}$ In our example, this is most likely to be the downstream firm. As a result, we expect that a higher proportion of the value of the invention is likely to be captured by the downstream firm than would be the case otherwise. However, this kind of asymmetric distribution in

"Of course, the research laboratory might play "hard to get" or might make some other form of commitment (such as walk ing away) that would enhance its negotiating position, at some risk of souring the deal. 


\section{the publication \\ of results continues}

to be the most

important form of

technology transfer in

oceanography. sults from federally funded research. The provisions of this act and other related legislation indicate to us that licensing is seen by Congress as some (admittedly imperfect) measure of the relevance of scientific research to achieving national goals. Scientific publication is not perceived as such.

Twelve years after the Bayh-Dole Act was signed into law, we have seen little technology licensing in the field of oceanography relative to that in other fields. But scientists and engineers at universities and nonprofit marine research laboratories are accomplished at disseminating basic research results through the scientific literature. Even in the face of policies that emphasize licensing, the publication of results continues to be the most important form of technology transfer in oceanography. Research results and data are available at low cost to a wide range of end users, including other oceanographers, environmental managers, and commercial firms.

We believe that the potential for technology licensing in oceanography is closely related to the potential for commercial uses of ocean resources. The commercial potential of the oceans depends in part upon a continued deepening of understanding about natural oceanic phenomena, which is a task for basic oceanographic research. A recent National Academy study finds that "much of the knowledge that is being used today in applications was developed 20 to 30 years ago by scientists simply following their own interests" (Wunsch, 1993). In the long run, it is likely that expanded economic benefits (and increased technology licensing) will result from the continued funding of basic oceanographic research, and it may be that this policy is superior to one that encourages applied research through technology licensing in the short run.

\section{Acknowledgements}

This work has been supported by the Office of Naval Research grant N00014-93-I-0028, and NOAA through grant NA26AD0156 to the Massachusetts Center for Excellence in Marine and Polymer Sciences. We thank Jim Broadus, Dave Gallo, Eric Hartwig, and two anonymous referees for careful reviews. WHOI Contribution 8230 .

\section{References}

Allen. B., 1991: Choosing R\&D projects: an informational approach. Am. Econ. Assn. Pap. \& Proc., 81, 257-261.

Arow, K.J., 1962: Economic welfare and the allocation of resources for invention. In: The Rate and Direction of Inventive Activity: Economic and Social Factors. NBER Conference No. 13, Princeton University Press, Princeton, NJ, 609-626.

1985: The economics of agency. In Principals and Agents: The Structure of Business, J.W. Pratt and R.J. Zeckhauser, eds., Harvard Business School Press, Boston, MA, 37-51.

Berman, E.M., 1990: The economic impact of industry-funded university R\&D. Res. Pol'y, 19, 349-355.

Broadus, J.M.. P. Hoagland and H.L. Kite-Powell, 1988: Determining the structure of the United States marine instrumentation industry and its position in the world industry. WHOI-88-55, Marine Policy Center, Woods Hole Oceanographic Institution, Woods Hole, MA, 99 pp.

Brockoff, K., 1992: R\&D cooperation between firms-a perceived transaction cost perspective. Manag. Sci., 38, $514-524$.

Brown, G.E., 1992: Rational science, irrational reality: a congressional perspective on basic research and society. Science, 258, 200-201.

Chapman, G., 1992: Push comes to shove on technology policy. Tech. Rev., 96, 43-49.

Council on Competitiveness (COC), 1992: Industry as a customer

understanding about the value of new knowledge provides an incentive for the research laboratory to learn about downstream markets.

The terms of transaction may be an important aspect that helps to compensate for the asymmetric distribution in understanding about the value of new knowledge. Recent research has focused on socalled "two-part tariff," $t$, which involves a fixed fee, $f$, paid up-front and a royalty, $r$, that is usually (but not always) a linear function of the commercial firm's output of the product. If we represent unit output by, $x$, the two-part tariff is $t=f+r(x)$. The terms of a technology licensing agreement might range from a pure fixed fee $(r=0)$ to a pure royalty $(f=0)$. The use of a royalty provides a form of risk-sharing between both parties, and Katz and Shapiro (1986) cite studies that find that most licensing agreements employ a two-part tariff. If a royalty is employed, then the research laboratory's financial renumeration depends upon the downstream firm's product output, which presumably is observable, instead of a potentially opportunistic signal of (unobservable) value from the downstream firm during the negotiation. The selection of the optimal fixed fee and royalty can still be problematic, and this problem is analogous to problems in the natural resource management (Teisberg 1980).

Technology licensing can be costly (Brockhoff, 1992). These "transactions costs" can originate from many sources, but they include those associated with the identification of potential licensees, negotiation expenses when markets are thin (few licensees), uncertainty associated with understanding the value of new knowledge, establishing intellectual property protection (obtaining patents) and other legal requirements, opportunism on the part of the licensees during the negotiation or in a long-term relationship. Recent federal legislative enactments and the efforts of many research laboratories to smooth technology licensing activities have been directed at reducing these costs. Transactions costs may be reduced by these efforts, but they will not disappear. The existence of transactions costs implies that not all types of technology licensing efforts are worthwhile. 
of the federal laboratories. Washington (September), $20 \mathrm{pp}$.

Dasgupta. P. and P. David, 1986: Information disclosure and the economics of science and technology. In: Essays in Honour of $K$. Arrow, G. Feiwel, ed., MacMillan, London. 519-542.

Dasgupta. P. and E. Maskin, 1987: The simple economics of research portfolios. Econ. J, 97, 581-595.

Feller, I., 1990: Universities as engines of R\&D-based economic growth: they think they can. Res. Pol'y, 19, 335-348.

Gaffney, P., 1992: Technology transfer act opportunities between government labs and industry. Proc. Oceanographic Partnerships: Navy and Industry. Marine Technology Society, Washington, 7-17.

Gallini, N.T. and B.D. Wright, 1990: Technology transfer under asymmetric information. Rand. J. Econ. 21, 147-160.

General Accounting Office (GAO), 1991: Technology transfer: federal agencies patent licensing activities. RCED-9180, Washington (April), $32 \mathrm{pp}$

Hoagland. P. and H.L. Kite-Powell. 1989: Technology transfer and intellectual property management in the field of oceanography. Internal Report, Marine Policy Center. WHOI, Woods Hole, MA, $68 \mathrm{pp}$.

Katz, M.L. and C. Shapiro, 1986: How to license intangible property. Quart. J. Econ., 101, 567-589.

Kaysen, C., 1966: Federal support of basic research. Minerva, 4, 254-272.

Mansfield, E., 1991: Academic research and industrial innovation. Res. Pol'y, 20, 1-12.

MacDonald, C. D., H.E. Deese, C.F. Keown and A.L. LaBarge, 1991: Is national ocean R\&D funding being short-changed? Sea Tech., 32, 35-40 (August).

McTague, J. P., 1988: Technology: wielding a three-edged sword. In: Federal Lab Technology Transfer: Issues and Policies, G.R. Bopp, ed., Praeger. New York, 3-8.

National Science Board (NSB), 1991: Science \& Engineer- ing indicators. NSB 91-1, U.S. Gov't Ptg. Ofc., Washington. 487 pp.

National Science Foundation, 1982: Federal funds for research and development, fiscal years 1981, 1982, and 1983. NSF 82-326. 188 pp.

Nelson, R.R., 1986: Institutions supporting technical advance in industry. Am. Econ. Assn. Pap. \& Proc., 76, 186-189.

Ocean Studies Board (OSB), 1992: Oceanography in the Next Decade: Building New Partnerships. National Academy Press, Washington. 202 pp.

Reinganum. J.F., 1989: The timing of innovation: research, development, and diffusion. In: Handbook of Industrial Organization, vol. 1, R. Schmalensee and R.D. Willig, eds., Elsevier Science Publishers, New York. $849-908$.

Rottenberg, S, 1968: The warrants for basic research. In: Criteria for Scientific Development: Public Policy and $\mathrm{Na}$ tional Goals, E. Shils, ed., MIT Press, Cambridge, MA, 134-142.

Smith, G.V. and R.L. Parr, 1989: Valuation of Intellectual Property and Intangible Assets, John Wiley \& Sons, New York. 450 pp.

Task Force on the Health of Research (TFHR), 1992: Report of the task force on the health of research: chairman's report to the Committee on Science, Space, and Technology, U.S. House of Representatives. U.S. Government Printing Office, Washington (July), $19 \mathrm{pp}$.

Teisberg, T.J., 1980: Federal management of energy and mineral resources on the public lands. Bell J. Econ., II, $449-465$.

Tirole, J., 1988: The Theory of Industrial Organization, MIT Press, Cambridge, MA, 479 pp.

Wunsch, C., 1993: Marine sciences in the coming decades. Science, 259, 296-297. 